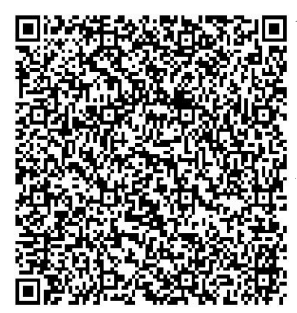

\title{
DYNAMICS OF TOURISM GROWTH AND ITS IMPACT ON AN EMERGING DESTINATION: A STUDY ON GANGTOK, SIKKIM
}

\author{
Anu Chandran*
}
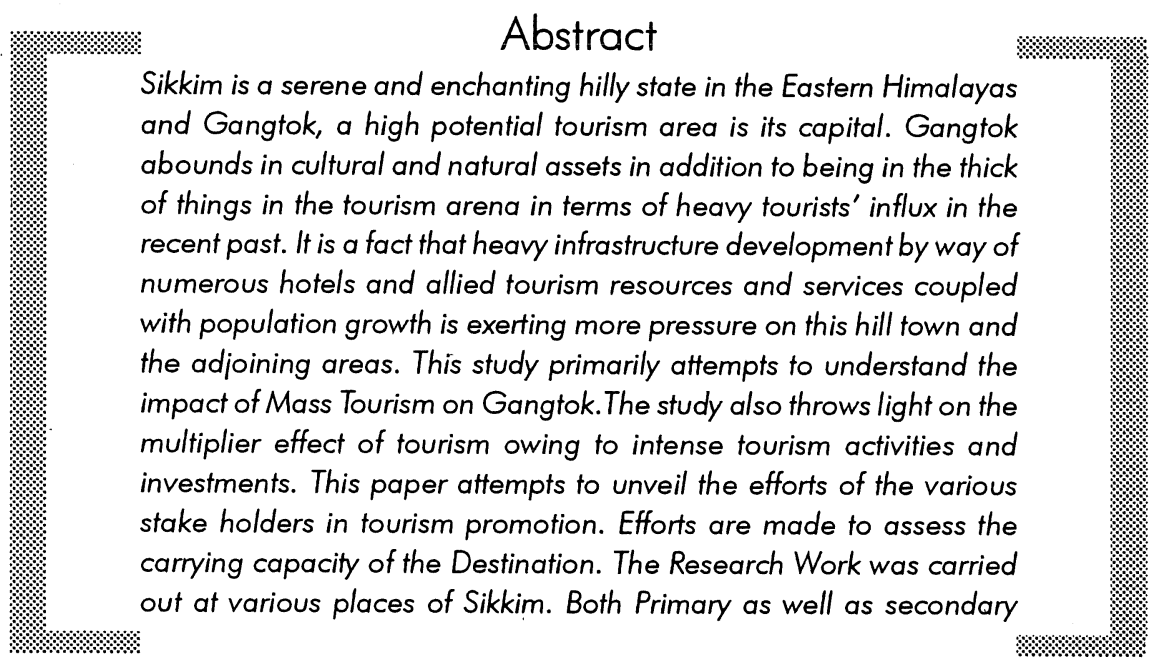

* Lecturer, Dept. of Tourism Studies, Pondicherry University, Email: anoos_ind@yahoo.co.in 
sources were utilized for the study. The primary sources included the interviews with experts and consultants viz. the Tourism Dept, Travel Agents and NGO's, Eco Tourism Promotion Agencies, ECCOS, KCC and the Tourists.

\section{Introduction}

Gangtok is emerging as an awesome Hill Tourism destination with the finest hospitality and outstanding amenities apart from the spellbound natural attractions. The location of many Buddhist Monasteries rich with frescoes, religious paintings in silk and statues of Buddha's various incarnations, makes it a perfect soothing place. Gangtok, balances precariously on steep mountain slopes at an altitude of 5,500ff above sea level. After Sikkim was merged with India there has been a sea change in and around Gangtok. Tourists are highly inclined to visit the sites like Fambong Lho Wildlife Sanctuary, Rumtek village and Tsomgo Lake. Tsomgo Lake-a holy lake, at an altitude of 12,210 feet, $40 \mathrm{kms}$ from Gangtok is set amidst alpine pastures and high snow covered mountains. Though the area falls in the restricted zone of Sikkim and does not have any permanent settlement, this site attracts a large number of domestic tourists mainly for recreation.

The most conspicuous attraction of Sikkim is its excellent Bio-diversity. The monastic culture is also well preserved. Gangtok also boasts of the Namgyal Institute of Tibetology, Orchid Sanctuary and a large Chorten(Tibetan Stupa). The Destination is also home to the famed Orchids which are indigenous to Sikkim. Trekkers and Mountaineers frequent the place for adventurous expeditions and the rivers Teesta and Rangeet offers excellent river rafting experience. The lodging houses of Gangtok are extremely popular.

\section{Methodology}

The data for this paper is based on the field visits to various parts of Sikkim. Expert opinion was collected through personal interviews with Tourism Professionals, Officials, Travel Agents, NGO's, and staff of organizations like ECCOS, KCC etc. Mainly the Destination planners and designers were interviewed to infer the set of objectives. Discussions with social and environmental activists also provided invaluable leads to further the course of this study. 


\section{Tourism in the Land of Mystic Splendour}

Gangtok is a captivating destination in the foothills of the majestic Himalayas with its architectural marvels and delightful locales. Gangtok is today a busy town bustling with hectic activity. The destination offers the tourists all modern amenities of comfort and pleasure. Gangtok has developed into a cosmopolitan flavor where old world charm and hospitality exist along with the technology boom.

Gangtok was a small hamlet until the construction of the Enchey Monastery in 1840 which made it a pilgrim center. It became a major stopover between Tibet and British India at the end of the $19^{\text {th }}$ century. Following India's independence in 1947, Sikkim became a nation state with Gangtok as its capital. Now, comprising of a mixed population, the city offers a vibrant mix of cultures. Gangtok is a renowned center of Tibetan Buddhist culture and learning and offers a spectacular view of the Kanchenjunga.

Some sections of tourists are enthusiastic about repeatedly visiting places like Chorten, Ganesh Tok and Hanuman Tok, the Flower Exhibition Center and the Enchey Monastery, which is a 200 year old monastery famous for the mask dance called 'Cham'. The helicopter service between Gangtok and Bagdogra is relished by the tourists. Scientific Planning and Environmental Engineering holds the key in the tourism development of Gangtok. Now let us briefly examine the areas which require intensive attention. 1) Improved transportation. (Gangtok can take a cue from destinations like Shimla, to adopt CNG operated vehicles, battery operated vehicles and trained horses in hilly terrains which helps to avoid vehicular traffic and thereby pollution and congestion.) 2) Cleanliness and good civic sense. 3) Water supply. 4) Environment protection. 5) World class airport. 6) Slum eradication. 5) Better housing facilities. 6) Parking facilities (Multistoried). 7) Modern communication facilities. 8) Sports complexes and stadiums. 9) Recreation centers and parks. 10) Sewage and garbage treatment facilities. 11) Shopping Malls. 12) Eco-friendly resorts.

In sync with tourism promotion there are some related issues which speedens the destination lifecycle. If we analyze the reasons behind prime destinations reaching the saturation point in brisk pace, we can find that due to lack of measures for enforcing positive checks on overall development, the destination suffers utterly. In this connection, every stakeholder in the tourism industry has to keep in mind the fact that in tune with the idea of attracting large number of tourists by tapping the resources of the destination, it should not be lost forever. The saying 'catch them young', fits the bill in the case of tourist destinations, i.e., by learning from the past experiences of exploited destinations, the policies for developing an upcoming 
destination may be formulated. We shall now examine the one important issue faced by an emerging destination like Gangtok, which if not controlled leads to exploitation and devastation. It is the alarming pace at which the fresh water supply is getting affected. When the tourist traffic is high, proportionately there will be an over consumption of water. Eventually this will lead to acute shortage of even drinking water. If the authorities look into the matter with more seriousness in the initial stages, the problems like over consumption of power and water can be minimized.

It evolved as part of the study that to decongest a place like Gangtok, on the lines of the Western countries, the outskirts and suburban areas might be opened up for the construction of buildings and apartments. Known as Satellite Cities, this helps in the development of exotic places within $25 \mathrm{~km}$ range.

It goes without saying that without local community participation no project can be successful. The Tourism Corporation of Gangtok needs to organize comprehensive programs to make the people aware on the various dimensions of tourism development. The Corporation can also figure out the scope of subscribing to the idea of a sister city concept. This concept has gained wide coinage across the world. It implies forming a strong bond with a city/town located anywhere in the world having similar features and characteristics. It is a mutually beneficial practice wherein both the places are reaching a win-win situation. It also conforms to transfer and sharing of ideas and practices. Gangtok can also find a sister city, forge firm relationship and try to gain through co-operation and assistance. Gangtok Tourism can steadily develop through FDI. Attracting FDI judiciously and in a planned manner can be highly beneficial. In tandem, the establishment of new ventures like food courts, go-karting centers, multiplexes, etc, will definitely give a push to the tourism industry. Such most modern projects provide large scale employment opportunities. The investment boom coupled with quality tourism leads to greater multiplier effect. The improvement in the quality of living of people of Gangtok also has contributed a great deal to the positive economic impacts especially through multiplier effect. Being an upcoming destination, Gangtok Tourism does not have many promoters and developers. Policies like PPP (Public Private Participation) are waiting to get grounded. Due to this aspect even the role of the private sector as one of the stakeholders in tourism promotion is very limited. Similarly, the social organizations and NGO's are yet to surface pronouncedly in tourism planning and development. At the same time, the local community participation is very explicit in tourism operations. 


\section{Mass Tourism and Environment Impact}

Gangtok is in the formative stage of tourism development, but even so, the tourism related environmental effects are very evident in the more frequented places and is likely to be aggravated. Environment degradation is a cause of grave concern in Gangtok and at the same time the impact in urban Gangtok cannot be attributed solely to tourism activity. It is also because the existing thresholds have been surpassed. The type of degradation referred to here is caused when the city provides for more numbers than actually planned for. It may be pointed out that it is more pronounced in Gangtok.

\section{Degradation of Urban Eco-system}

Urban Ecotourism is ecological tourism that takes place within the city. According to John Shores, "Urban Ecotourism makes urban spaces more livable while ensuring protection of the natural resources and ecosystems that sustains us." The degradation of urban environment is reflected in the excessive construction in Gangtok. The hill station is fastly getting reduced to a concrete jungle with the constructions creating havoc to the progress of tourism in the state. Tourism in urban areas is usually dictated more by human or institutional factors than natural phenomena associated with seasons and climate. Like in all urban areas, litter is a problem in Gangtok and litter management is required to be addressed on priority basis at the destination. Another important issue which was raised confirms to the pollution of water sources which is an offshoot of the lack of adequate sewage facilities and points to the urgent need for attending to physical planning.

The large number of visitors coming from the hot plains and the ever increasing migrant population is found to be detrimental to the best interests of tourism promotion in the destination. In this connection, the primary threat to bio-diversity from tourism is identified to be fuel wood use and excess grazing. Yet another environment problem from trekking tourism in Gangtok is detected to be poor garbage management. Sikkim Bio-Diversity and Eco-tourism Project (SBE) is actively engaged in stringent activities for bio-diversity conservation. SBE was designed to generate incentives to conserve at more than one operational scale. SBE used participatory strategies to 1) Increase community and private sector conservation, 2) Increase economic returns from Ecotourism services and enterprises, and 3) Contribute to policies that meet conservation and Ecotourism goals. Among their key achievements include an overall reduction in fuel wood consumption generated by tourism services. Another noteworthy feature of the project is that the participation by the private sector and local communities in Policy discussions has increased, as the Government of Sikkim adopts project models of consultation and decision 
making. The Govt. has also sought and acted upon technical assistance given by Project staff. One case in point is the refining of Tourism Development Proposals.

Since there had been little prior study of bio-diversity in the project sites, there was considerable investment of staff and project resources in collecting and establishing base-line data. Staff and collaborators have made great strides in establishing base-line data for this hot spot that provide the foundation for assessing the impact of current and future activities, and guiding policy development.

The key factors that are identified to be addressed in future programs include a) Stakeholder decision making power over resource management, b) Availability of alternatives to the resources under threat c) Stakeholder capacity and interest to monitor resource status, d) Lobbying for enabling policies.

\section{The Role of ECCOS}

The Eco-Tourism Conservation Society of Sikkim is a society working towards the development and promotion of Sikkim as a premier Eco-Tourism destination by promoting research in conservation and sustainable development. They encourage and facilitate the adoption of environmental studies and ensure that the development of ecotourism has positive and beneficial linkages for the marginalized communities living in the rural and mountain areas. It strives to protect and enhance their social and cultural integrity by promoting self-reliant community development initiatives that are environmentally and economically sustainable. The ECCOS actively engage with state and national bodies in policy formulation and contribute towards the publication of research works and articles on ecotourism, conservation and promotion. The society advocates a development process that is growth oriented, equitable and founded on good governance.

\section{Major Issues and Threats}

- De-forestation for tourism activities

- Inconsistent garbage disposal and waste management

- Lack of developing agricultural practices to deal with soil erosion

- Poaching and purchase of wildlife products

- The disruption of vegetation patterns

- The disruption of breeding and nesting behavior which increases species vulnerability 
- Lack of synergy between the various departments, for eg; the Tourism and Forest Departments

- Gangtok is a seismic prone zone, and if the constructions go haywire, it may prove disastrous to the place

- Pollution of water sources and lakes because of the lack of sanitation management ethics

- Movement of vehicles in the wildlife areas

- Migrant population to Gangtok in search of better avenues, disturbing the carrying capacity of the place

- Lack of proper site management knowledge

- Air pollution which occurs due to metal pollution and toxic chemicals which affect the health of both tourists and local community

\section{The Traditional Design Elements of Gangtok and Natural Landscaping}

Gangtok has a great wealth of traditional architecture in wood, mud, bamboo and traditional wood work, carvings, fabrics, a rich heritage of art work and hence the design elements that can be used in building exteriors and interiors to make lodges and hotels uniquely 'Sikkimese.' The traditional Bhutia, Lepcha and Nepali design elements are maintained in the buildings.

It is stated that the best landscaping in Gangtok is done by nature. Gangtok possesses a great wealth of natural and cultural attractions and does not need any large investment products or sky rocketing structures, which may cause a scar to the landscape of Gangtok, given the nature and chemistry of the place.

\section{Ecotourism Marketing in Gangtok}

Ecotourism is part of the general growth of tourism in Gangtok and reflects increased environmental awareness and the desire for more authentic natural and cultural experiences. There is concern that unplanned and unregulated tourism growth in natural areas of the destination can lead to pronounced negative environmental and cultural impacts. 
The general feeling among the respondents, comprised of mainly Tourism officials and developers, was that in order to promote ecotourism, one should be conscious of protecting the ecology and environment of any place visited and must ensure that no destruction is caused nor garbage left behind while respecting the local sentiments and the way of life of the local people. Ecotourism, being a highly sensitive concept and activity, has limitations regarding dynamic promotion and publicity. This is because the destination at a particular point of time may be opened up to a limited number of visitors, enforcing positive check by maintaining the carrying capacity. Aggressive marketing is not characteristic of ecotourism and in the context of Gangtok; most of the recommendations pointed out that ecotourism unlike other forms of commercially viable tourism should not be viewed from the business motive but from the pedestal of aesthetics and appreciation.

Nonetheless, there is considerable potential for ecotourism in Gangtok to positively contribute to conservation and economic development at a variety of scales. It also provides income generating opportunities to traditionally remote and marginal communities. The challenge lies in developing strategies that help create enabling policy frameworks, support and link the various scales and type of operation that are necessary for successful organization of ecotourism and create broad-based support for ecotourism objectives and principles.

The compilation of data with reference to the attributes of ecotourism marketing in Gangtok is as follows:

1) Being an ecotourism haven, Gangtok attracts lots of tourists from far and wide and the mode of transport used by the tourists pollutes the serene atmosphere of the place. Improving the transport facilities and regulating the movements in sensitive zones will definitely give a facelift to the overall ambience.

2) The goals of ecotourism marketing should be to promote the activities like soff trekking and adventure tourism.

3) Yet another inference is that Gangtok should subscribe to the principles of 'quality tourism' and not 'quantity tourism.' Gangtok being a sensitive and rich bio-diversity region has to regulate the number of visitors especially during peak season without compromising on the revenue. The best way is to opt for quality tourism. High spending tourists from affluent countries can be the target audience, wherein the number of visitors will be minimal even when financially the destination is benefited.

4) Emphasis may be laid on organizing FAM tours for travel agents and travel writers to make the marketing activity effective and action oriented. 
5) The target groups for marketing in the domestic sector were identified as the upper middleclass, while in the foreign sector; the view was that Asian and European markets should be tapped.

6) Both the guest and host should be instilled with the feeling of respecting the frailty of the cultural and ecological resources of Gangtok.

The pertinent question to be asked is what makes the product, whether trek or soft adventure or an ecotourism one. The answer is very simple, ie, if the ecotourism norms are maintained in the operation of the trips, it is an ecotourism product, for instance bringing back the garbage using local products without depriving the local supply is a case in point. Briefing clients about the norms, such as not plucking plants/flowers or littering, briefing about proper clothing and when possible educating local community about the ecotourism norms that distinguishes an ecotourism product will be extremely beneficial to the destination. In the absence of adequate participation in planning and management, local communities often bear the cost of tourism development and protected area management, gaining little or nothing in the way of income generation opportunities and suffer from restricted access to resources.

Certain infrastructural deficiencies are also observed while promoting ecotourism. They are:

- The need for more quality rooms and up gradation of hotel facilities in and around Gangtok.

- The Tourism Corporation and private sector can plan for supplementary accommodation establishments.

- The exploratory role of stakeholders in packaging new destinations.

- Critics argue that visits to environmentally fragile areas, often during sensitive periods, can affect breeding and regeneration very badly. (Areas and sites opened for ecotourism may eventually lead to mass tourism and a range of negative impacts.)

Gangtok is identified as a bottleneck center of accommodation especially during peak season. An alternative may be to develop good camping sites.

\section{Active and Proposed Strategies}

- Establishment of four centers for the promotion of Village Tourism.

- Dynamic capacity building measures especially for local people and local authorities. 
- Efforts for new product development.

- Integration of marketing activities.

- Effective energy management schemes.

- Enforcement of pollution control measures.

- Deployment of Tourism Police and Guards in all tourist spots to check, control and ensure that tourist facilities products and services are not misused. They are empowered to provide protection and guidance.

- Development of Eastern Himalayan Circuit.

- Facilitating investor friendly climate for entrepreneurs in the tourism sector.

- New eco-friendly hotels are proposed to be set up.

- Efforts to impart proper training and education to tourism professionals on conservation of the environment and socio-cultural resources.

- Diversification of various tourist sites.

- Improvement of infrastructural facilities especially laying of roads.

- Activation of customized itineraries.

\section{Conclusion}

Gangtok possesses lots of natural and cultural resources and tourism seems to be one of the few viable industries. This study has brought to light the fact that like any other upcoming tourist destination of India, there is a dire need to enhance the civic sense of both the hosts and the guests, especially in view of the Gangtok situation. Gangtok falls in the major biodiversity zones of the world. The irony lies in the fact that Gangtok is not so much known for its ecotourism potential as is the case, but tourists, both domestic and international, are flocking in, considering the scope of leisure, adventure and recreation. It is a fact that Mass Tourism has created lots of impacts on various tourist spots in Gangtok and has to an extent affected the economy, environment and socio-cultural aspects of the region and also the carrying capacity. The mass tourist traffic of a different sort, without realizing the ecological importance is posing some threats to the organization of the destination. The analysis of data throws light on the lack of scientific studies being conducted to understand and explore the biological aspects of the place, which gets reflected even in the course of tourism activities. Such scientific studies relates to even tourism 
development in Gangtok. The Environment Impact Assessment and other such feasibility studies are to be conducted and the outcome is sure to be absolutely rewarding to the future of tourism industry. Only a holistic approach in terms of pro-active stakeholder participation, awareness among tourists and host communities, scientific planning, technical studies and a conducive socioenvironmental climate can save the day for tourism, rather eco-friendly tourism in Gangtok. The initiative of educating the local people on value perception and sustainability is a highly commendable and fruifful exercise.

\section{References}

- Archer B H, Demand Forecasting in Tourism, University of Wales Press, 1976.

- Burkart A J The Management of Tourism, London Heinemann, 1975.

- Butler R W, The Social Implication of Tourism Development, 1974.

- Christopher J Holloway, The Business of Tourism (Fourth Edition), 1994.

- Coleman, S. and Crang M, Tourism: Between Place and Performance, Berghahn Books.

- Donald E Hawking, Tourism Planning and Development, George Washington University, 1980.

- Lundberg Donald, The Tourist Business, Caliners Books, 1974.

- Mclntosh R W, Tourism Principles, Practices and Philosophies, Ohio, Grid, 1977.

- Matheison Akister, Tourism: Economic, Social and Physical Impacts, London, Longman, 1982.

- Pearce, D, Tourist Development, London, Longman, 1981.

- Raymond F, Ecological Principles for Economic Development, London, John Wiley, 1978.

- White J, History of Tourism, London, Leisure Art, 1967.

- Young George, Tourism Blessing or Blight, London Penguin, 1973.

\section{Webliography}

- www.national trust.org/heritage-tourism 